\section{Narrowband imaging colonoscopy with a transpar- ent hood for diagnosis of a squamous cell carcinoma in situ in the anal canal}

Anal cancer is a relatively rare malignancy [1]. An analysis of the National Cancer Data Base showed that most patients with anal carcinoma (71.1\%) required invasive treatments such as chemoradiation therapy with or without surgery, and the 5-year overall survival for these patients was $58.0 \%$ [2]. Anal squamous cell carcinoma in situ (CIS) accounts for almost $10 \%$ of all anal carcinomas [3]. Here we present a case of anal canal squamous cell CIS incidentally detected in a patient at low risk of developing anal cancer. The presence, histology, and spread and depth invasion of the tumor were correctly diagnosed by narrowband imaging (NBI) with magnification.

An asymptomatic 62-year-old woman underwent conventional colonoscopy, which revealed an ill-defined, flat lesion with scattered reddish spots at the dentate line ( $\bullet$ Fig. 1).

NBI without magnification showed a welldemarcated brownish area, $25 \mathrm{~mm}$ in size, as well as scattered brown dots at the same site ( $\bullet$ Fig. 2 a).

NBI with magnification disclosed dilated and tortuous capillaries, mimicking intraepithelial papillary capillary loops in the esophagus ( $\bullet$ Fig. $\mathbf{2}$ b, c). Lugol chromoendoscopy revealed a well-demarcated, unstained area corresponding to the brownish area seen with NBI ( $\bullet$ Fig. 3 ).

A biopsy specimen was taken for histological evaluation, which suggested squamous cell carcinoma, and transanal resection was carried out. On histological ex-

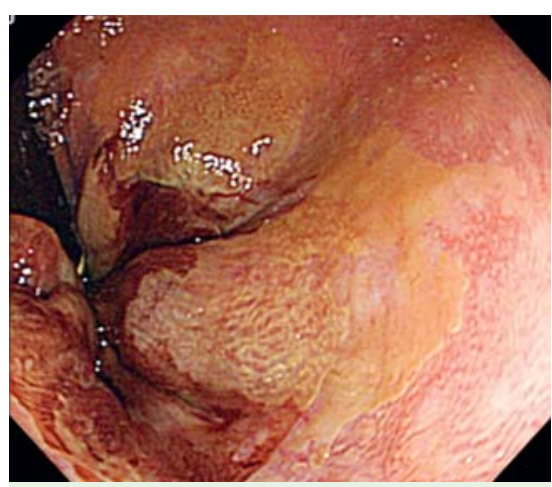

Fig. 3 Lugol chromoendoscopy showing a well-demarcated, unstained area corresponding to the brownish area shown by narrowband imaging.

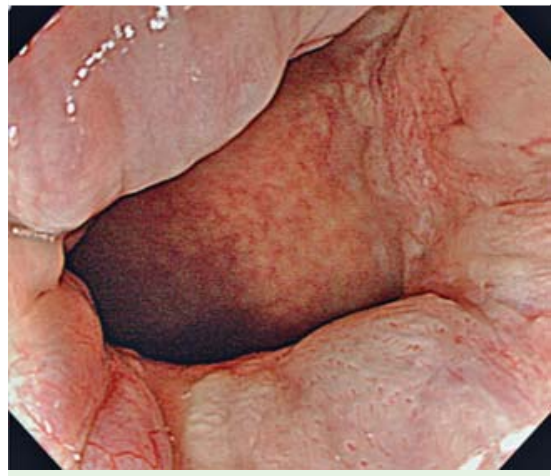

Fig. 1 Colonoscopy with a transparent hood showing an ill-defined, flat lesion, slightly reddish at the dentate line.

amination, the resected specimen showed squamous cell CIS with high grade intraepithelial neoplasia ( $\bullet$ Fig. 4); the surgical margin was free of tumor.

To the best of our knowledge, this is the first report of an anal CIS detected by NBI. NBI with magnifying endoscopy showed an abnormal vascular pattern of intraepithelial papillary capillary looping, which suggested that the lesion was a squamous cell cancer [4]. The spread of this tumor was also clearly demarcated with NBI. In the present case, we used a magnifying colonoscope with a transparent hood [5]. A transparent hood also ensures good vizualization of the anal canal without retroflexion of the colonoscope. Therefore, NBI colonoscopy with a transparent hood is useful for screening for anal squamous cell carcinoma.
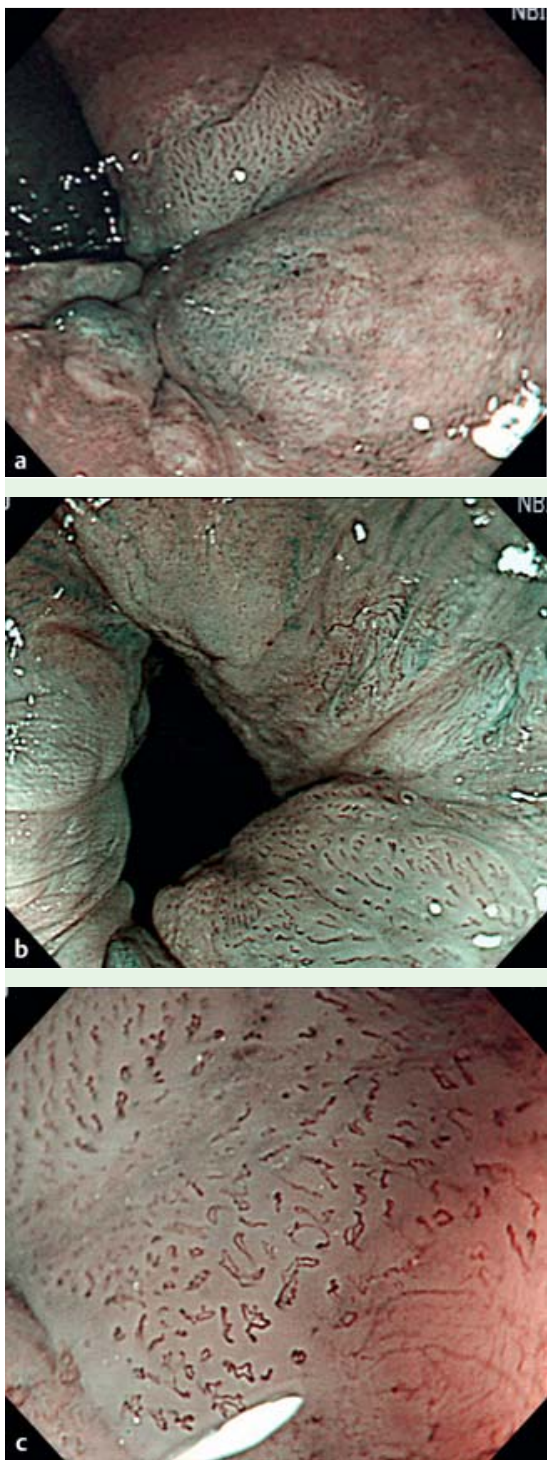

Fig. 2 a Narrowband imaging (NBI) without magnification showing a well-demarcated, brownish area, $25 \mathrm{~mm}$ in size, and scattered brown dots at the same site. $\mathbf{b}, \mathbf{c} \mathrm{NBI}$ with magnification showing dilated and tortuous capillaries mimicking intraepithelial papillary capillary loops in the esophagus.

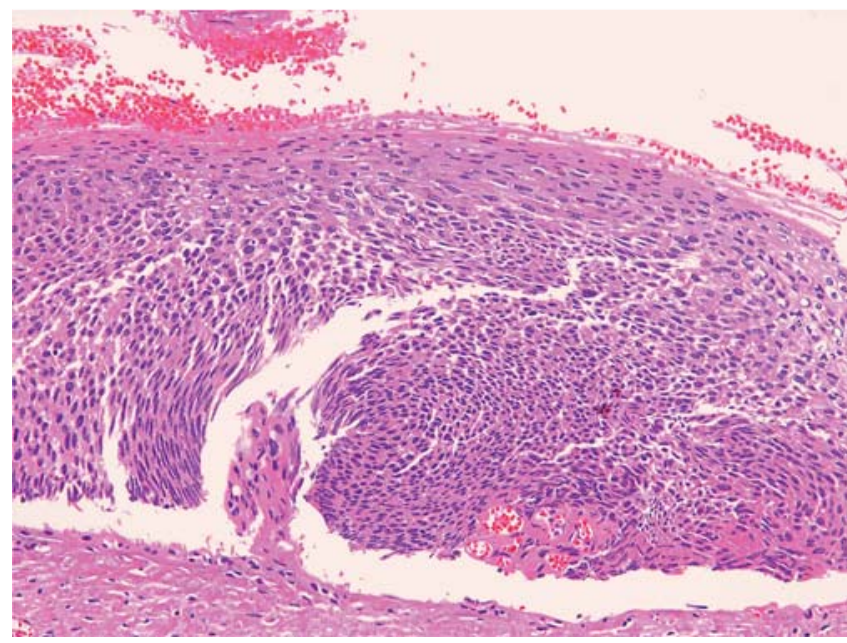

Fig. 4 The resected specimen was a squamous cell carcinoma in situ with high grade intraepithelial neoplasia. 
Competing interests: None

Endoscopy_UCTN_Code_CCL_1AD_2AB

Y. Oono ${ }^{1,2}$, K. Fu' ${ }^{3}$, H. Nakamura ${ }^{4}$, Y. Iriguchi ${ }^{2}$, A. Yamamura ${ }^{5}$, D. Kishi ${ }^{2}$, J. Oda ${ }^{2}$, H. Ikematsu ${ }^{1}$, M. Mizutani ${ }^{2}$, S. Takayanagi ${ }^{2}$, Y. Tomino ${ }^{2}$

1 Department of Gastroenterology, National Cancer Center Hospital East, Chiba, Japan

2 Department of Gastroenterology, Tokyo Metropolitan Cancer Detection Center, Tokyo, Japan

3 Department of Gastroenterology, Juntendou University Nerima Hospital, Tokyo, Japan

4 Department of Gastroenterology, Chofu Surgical Clinic, Tokyo, Japan

5 Department of Pathology, Tokyo Metropolitan Cancer Detection Center, Tokyo, Japan

\section{References}

1 Clark MA, Hartley A, Geh JI. Cancer of the anal canal. Lancet Oncol 2004; 5: 149-157

2 Bilimoria KY, Bentrem DJ, Rock CE et al. Outcomes and prognostic factors for squamouscell carcinoma of the anal canal: analysis of patients from the National Cancer Data Base. Dis Colon Rectum 2009; 52: 624-631

3 Joseph DA, Miller JW, Wu X et al. Understanding the burden of human papillomavirusassociated anal cancers in the US. Cancer 2008; 113: $2892-2900$

4 Yoshida T, Inoue H, Usui S et al. Narrow-band imaging system with magnifying endoscopy for superficial esophageal lesions. Gastrointest Endosc 2004; 59: 288 - 295

5 Matsushita M, Hajiro K, Okazaki K et al. Efficacy of total colonoscopy with a transparent cap in comparison with colonoscopy without the cap. Endoscopy 1998; 30: 444-447

\section{Bibliography}

DOI $10.1055 / \mathrm{s}-0029-1244038$

Endoscopy 2010; 42: E183 -E184

(c) Georg Thieme Verlag KG Stuttgart · New York . ISSN 0013-726X

\section{Corresponding author}

\section{Y. Oono, MD}

Department of Gastroenterology National Cancer Center Hospital East 2-9-2 Kashiwanoha

Kashiwa City

Chiba 277-8577

Japan

Fax: +81-4-7134-6928

doc2adova@yahoo.co.jp 